Article

\title{
The Effects of the RCS's Application in the Value Added Tax Collecting Process on the Perception of SME Taxpayer in Korea's Trade Activity: Transparency and Fairness in Trade
}

\author{
Sung Man Yoon ${ }^{(1)}$ \\ Department of Business Administration, Seoul National University of Science and Technology, Seoul 01811, \\ Korea; ysm6123@seoultech.ac.kr; Tel.: +82-2-970-6440
}

Received: 29 August 2018; Accepted: 6 November 2018; Published: 10 November 2018

\begin{abstract}
Value Added Tax (VAT) is the largest source of global tax revenue. However, it faces issues of tax avoidance, such as the black-market and missing trader intra-community fraud. Many studies have postulated that the introduction of the Reverse Charge System (RCS) will contribute to the enhancement of transparency and fairness in trade for small and medium enterprises (SMEs) that supply goods or provide services. This study analyzes SME taxpayers' perception of transparency and fairness in trade resulting from the introduction of the RCS into the South Korean VAT system. In B2B transactions that handle gold, copper, and steel scrap, large companies often abuse their bargaining power over smaller firms by not paying VAT with their purchase or reducing the prices to equal VAT, leading to low trade transparency. When it comes to gold, copper and steel scrap trading, the imbalance in bargaining power results in one of the parties being unable to reap maximum benefits because of unfairness. SMEs with relatively weak bargaining power suffer from unfair trading practices such as price cutting and the imposition of VAT by their counterparts. Since the introduction of the RCS, however, SME taxpayers appear to believe that trade fairness has improved. This study's findings reveal that SMEs are more likely to perceive improvement in trade transparency and fairness since the implementation of the RCS, indicating that the RCS has exerted a positive influence on SMEs. This study provides important policy implications for countries that intend to implement the RCS by offering empirical evidence of its benefits.
\end{abstract}

Keywords: SME sustainability; Reverse Charge System; trade fairness; trade transparency; Value Added Tax; tax collection system

\section{Introduction}

Value Added Tax (VAT) was first introduced in the 1970s (in the case of Europe, the 1960s) to generate revenues needed for economic development across the world. Revenues from VAT have increased steadily over the years with the expansion of the global economy. In South Korea, VAT makes up 29.2\% (approximately 54 trillion won) of the nation's total tax revenue at 185 trillion won as of 2015, and is one of the three major sources of tax revenue along with corporate and income taxes [1-3].

The current VAT operates on a taxation system in which sellers or vendors collect VAT in addition to the price of the goods or services provided to buyers [4]. VAT in South Korea is supported by an invoicing method (i.e., invoice credit method) where the tax amount due is calculated by deducting the input tax from the output tax [1]. However, limitations imposed on the VAT system by the invoicing method as such has led to the prevalence of missing trader intra-community (MTIC) fraud where firms file for bankruptcy after reclaiming the input tax without paying the output tax, and black-market 
fraud in which VAT is evaded by means of actual transactions without records such as credit card or cash receipts $[1,3,5,6]$. The VAT collection system is generally divided into two types. First, in Korea, the final VAT has the form of subtracting the input VAT from the output VAT. At this time, the input VAT becomes the seller's output VAT in the immediately preceding transaction step. Second, as with some European countries, the final VAT is the output VAT and later the input VAT is the return from the tax authority. In short, the above two ways to determine the final VAT are the difference between gross or net approach. In the case of the gross approach, additional VAT and refundable VAT exist at the same time, but when the net approach is applied, only one additional or refundable VAT exists. However, in both of the above forms, deductible and return are all possible in the normal state of the supply chain. If any one trader in the trade chain evades tax, deductible or return becomes impossible. Therefore, the cases presented in this study are notions that apply in most countries.

Despite numerous revisions of the VAT system in an effort to combat the aforementioned problems, tax avoidance continues to be a prominent and ongoing issue in South Korea. It first introduced the reverse charge system (RCS) for gold trade in 2008. It has now expanded to include trade in copper and copper scrap since 2014, and then all metal items including iron since $2016[1,2,7]$.

The RCS shifts the responsibility of filing and paying VAT from the seller or vendor, onto the buyer without making changes to the rights of the buyer in reclaiming the VAT paid, such as existing VAT [8]. The RCS makes it a rule that the recipient of goods or services has the obligation of payment of VAT instead of the person supplying the goods or providing the services $[6,9]$. Under the RCS, the buyer is held responsible for VAT payment, which eliminates existing problems of tax avoidance and delinquency caused by the seller or vendor being the VAT obligor $[3,8]$. It was anticipated that the implementation of the RCS for gold transactions will enhance its transparency and encourage fair practices in the precious metals industry, ultimately leading to an increase in the national revenue by preventing VAT avoidance and delinquency without increasing tax rates.

While the RCS does have benefits, some have voiced their concerns about possible side effects due to the drastic differences between the RCS and the traditional collection method. A considerable amount of transaction costs along with tax compliance costs can be incurred as a result of the restriction placed on the payment method during buying and selling of items under the RCS [2,6]. Furthermore, the introduction of the RCS has been accused of slowing down liquidity, as the conventional VAT collection system had allowed a seller or vendor to receive VAT from the buyer and use it as working capital until they make a payment to the Korea National Tax Service (NTS) [1]. Most of the previous studies provide institutional or policy implications for the introduction of the RCS [1-9]. In addition, many countries introduced the RCS through these proposals. However, research on the institutional effects of the RCS (i.e., reduction of tax evasion, fairness and transparency of transactions) is not active. The analysis of the effect of the introduction of the new system provides an opportunity for the system to develop further, so this study tries to coincide with this context.

Hence, this study attempts to analyze the effects of the RCS on VAT as perceived by South Korean taxpayers, with a focus on its effects on trade fairness and transparency. The paper particularly analyzes the perception held by small and medium enterprises (SMEs) as to how the introduction of the RCS has affected trade transparency and fairness. The scope of this study is limited to the intra-border transaction of Korean RCS. So, an explanation and analysis of cross-border and B2C transactions are omitted from this study. In particular, the application of RCS in international transactions that are of interest to the EU at present can be important. However, there is a limit to analyzing the RCS effect of international or B2C transactions, because survey subjects are Korean companies And the RCS implemented in Korea is applied only to B2B (it does not apply to B2C transactions).

This paper is organized as follows. Section 2 reviews the theoretical background of the RCS, and develops research hypotheses. Section 3 outlines the methodology, including the measurement of variables and extraction of research materials. Section 4 presents the empirical results including descriptive statistics, correlation and ordered probit model results, and Section 5 summarizes the study and presents its political implications. 


\section{Theoretical Background of Reverse Charge System (RCS) of VAT and Hypothesis Development}

\subsection{Literature Review}

RCS has been introduced in EU countries, and Canada, Singapore and Korea have also applied RCS to VAT. Although many countries have adopted RCS, prior studies that directly addresses the effects or outcomes of this RCS is not active. Most studies related to RCS are to propose or introduce RCS. As a representative study, Ainsworth [10] argues that the fundamental flaw allowing tax avoidance in the system is that a party is both responsible for the RCS and can claim VAT on the next sale. If a party has the certified software, it would take responsibility for filling the VAT return for a cross-border transaction. If the buyer and the seller in an intra-border trade is certified, the buyer can receive the credits with $0 \%$ VAT and file for a RCS.

Zee [11] built a proposal regarding the implementation of a RCS that shifts the collection of the VAT on the financial transactions. The mechanism that is embodied in the RCS approach to transfer the reverse charge on depositors to borrowers is a franking mechanism similar to the one used by corporations to frank dividends. This mechanism makes sure that the credits are derived from deposits that have in fact been reverse charged. And also, Ainsworth and Musaad [12] proposed to apply RCS of value added tax (VAT) in the six Member States of the Gulf Cooperation Council, in order to struggle with VAT frauds. Zee [11] and Ainsworth and Musaad [12] suggest the need to introduce RCS for VAT in international transactions and emphasize the effects of RCS. International trade may be important for economic partnerships, such as the EU or the Gulf Cooperation. However, this study focuses on RCS in Korea and analyzes its effects. Therefore, it is necessary to review literature on RCS in Korea.

As a representative study on RCS in Korea, Ki et al. [2] also proposed a mid- to long-term improvement plan for Korea's RCS. In Korea, the adoption of RCS is expanding and it is argued that it should be expanded to various items as EU members. Ki et al. [2] presented the results of the study that RCS application is needed not only for B2B transactions but also for B2C transactions. In particular, it raises the need for an analysis of trade transparency and fairness among RCS adopters that are directly related to this study.

Ponyatowski et al. [13] proposed indirect effects of the introduction of RCS, which is different from the studies that proposed the introduction of RCS. There are recent numerous changes in tax enforcement and monitoring, such as implementation and the extension of lists of goods applicable to the reverse VAT charge mechanism in EU Member States. And also Poniatowski et al. [13] reported that VAT Gap in 2014 declined by approximately 0.69 percentage point as indirect positive economic effects of the RCS. In addition, Chung and Yoon [1] analyzed the satisfaction of RCS and banking service among Korean companies applying RCS. This study suggests that most of the companies' satisfaction with RCS is high, especially SMEs' satisfaction. In addition, the results of the study suggest that the bank commission is a negative factor in the satisfaction of RCS when applying RCS. In particular, as a result of the introduction of RCS, the results of the Lamensch [14] showed that EU companies incurred RCS adoption costs of $0.02 \%$ of sales and that RCS had a compliance cost of about $43 \%$ higher than the invoice credit method Respectively.

\subsection{RCS of VAT}

Before explaining the RCS, it is necessary to review the current VAT transaction and its problems. In principle, VAT is collected through sellers or vendors who charge their trading partner with output tax, and then file and report the collected amount to the government [1]. It is a form of indirect tax where the tax obligor by law and the party that bears the actual burden of the tax are different. Thus, the provider has no other option but to pay the tax amount due to the NTS by the due date regardless of the provider's fiscal circumstances [8,15]. Furthermore, the invoicing method is used to collect the final VAT in South Korea. The VAT amount due is calculated by deducting the amount of input tax collected just before the transaction from the output tax [16]. 
South Korea's VAT system complies with the destination principle. Under the origin principle, VAT is imposed at the rate applied at the country of origin of the product. The difference in tax rates between the places of origin and destination creates discordance in VAT, which may lead to unfair trading practices [17]. The destination principle prevents inequality in international trade by imposing VAT on imports at the rate identical to that of the destination country and applying zero rate to exports [16].

Assuming that the transaction chain consists of the first producers $\mathrm{P}$, the intermediate traders A, B and $C$, and the final consumer $D$, the national tax service (NTS) receives VAT of $\$ 1$ from $P, \$ 1(=2+\triangle 1)$ from business $\mathrm{A}, \$ 3(=5+\triangle 2)$ from business $\mathrm{B}$, and $\$ 5(=10+\triangle 5)$ from business $\mathrm{C}$, which amounts to $\$ 10$ in total. If the final consumer pays VAT but the trade chain is destroyed, tax evasion occurs and transaction fairness breaks. If business B does not pay VAT $\$ 5$, which it received from business $\mathrm{C}$, to the Government Tax Office and at the same time closes business, business B becomes a missing trader. The government cannot collect $\$ 5$, and business A cannot get as much VAT deduction. In this case, one missing trader can break the entire trade chain, thereby tarnishing trade transparency, and ultimately bringing economic loss to the government and trading partners. The financial loss sustained by the government is especially large since each party involved in the chain often either leaves VAT unpaid to the tax office or becomes a delinquent [17].

The step-by-step collection procedure of VAT can be completed only when all parties involved in the trade chain carry out their duties, whose indirect nature creates many problems for the collection of VAT [18]. However, the recent rise of fund transfer, credit card transactions, and mobile payment as a replacement of cash payments may provide a solution to such issues of indirect tax. The RCS requires the buyer to pay for goods or services only to the seller or the vendor at the time of purchase, and then pay the incurred VAT directly to the government. The transaction chain in the South Korean RCS in B2B transactions is illustrated in Figure 1 (consumer D is not subject to the RCS). It begins with business A (buyer) purchasing gold, steel, or copper scrap from P (seller or vendor). Business A deposits the sale price, \$10, into P's account in a bank, which operates an RCS. Simultaneously, VAT \$1, $10 \%$ of the purchase price, is paid into the bank account of P's tax office through A's bank account.

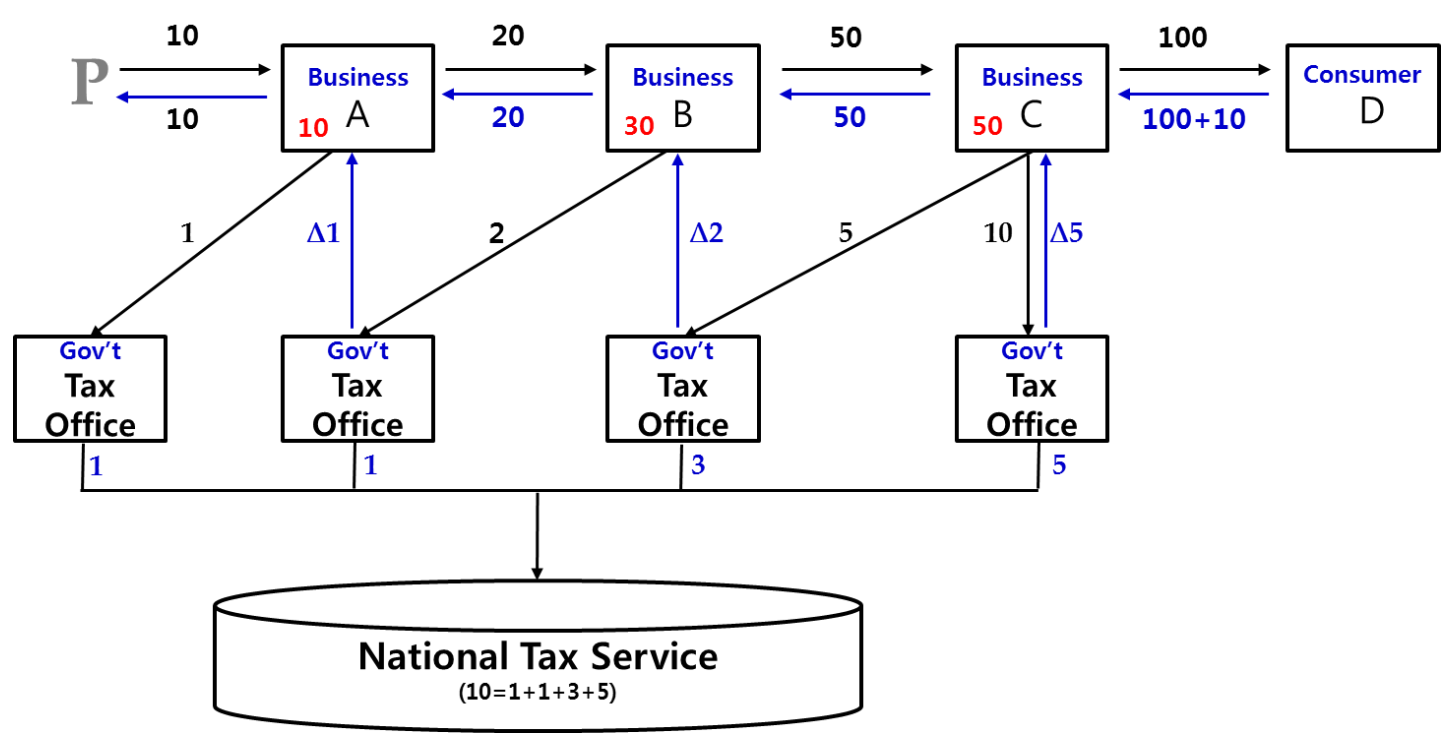

Figure 1. Value Added Tax (VAT) Reverse Charge System in Korea. Note: $\Delta$ and + refer to refundable and additional VAT, respectively.

As a seller, business A can sell the gold, steel or copper scrap to business B. Consequently, business B deposits the sale price of $\$ 20$ into A's bank account, upon which he also deposits $10 \%$ of the purchase price as VAT $\$ 2$ into the bank account of A's tax office. A's tax office then refunds the VAT \$1 that P's tax office received from business A into A's bank account. Businesses B and C undergo the same 
aforementioned procedure of VAT payment and refund, in which business B reclaims the VAT from its previous transaction with business A's tax office. Then, the B2C transaction between business $C$ and final consumer $\mathrm{D}$ is performed using the normal VAT system, with business $\mathrm{C}$ collecting the VAT of $\$ 10$ and paying it to the tax office. Under the RCS, the buyer is not paying the VAT to the seller or vendor, but directly to the tax office. Thus, even if the seller or vendor goes missing or delinquent, there will be no financial damage suffered by the government and the parties involved in the transaction as a whole, thus enhancing the fairness and transparency of trade.

In South Korea, the items liable to the RCS are gold, steel or copper scraps. These items share the following characteristics. First, it is considered customary for these items to be purchased in cash. Since they are recycled items or scraps recovered from an original item, the seller will often demand payment to be made in cash, heightening the risk of VAT evasion in the process. Furthermore, the trade chain, which consists of processing, treatment, manufacturing, selling and resell, clashes with the VAT chain, resulting in low trade transparency. Second, there is an imbalance of bargaining power between the seller (or vendor) and the buyer. RCS-applied items are high in demand because they can be used directly as raw materials in manufacturing in each transaction process. The buyer has weaker bargaining power than the seller or vendor. For worldwide international transactions, VAT adopts a consumer bureau taxation principle. In other words, the importing country collects the VAT of imported goods or services. Hence, the RCS implemented in Korea is applied only to B2B excluding B2C transactions.

The main content of the RCS should be to analyze the reduction effect of delinquent taxes as an introduction to the RCS. In general, from an academic perspective, it would be reasonable to conduct an analysis focusing on economic effects such as the reduction of delinquent taxes and reduction of tax evasion due to RCS adoption. However, this study is intended to focus on the non-economic effects of RCS users in the transaction practice from a qualitative perspective, rather than on the economic effects of the RCS. Thus, this study focuses on the transparency and fairness that SMEs perceive as an introduction to the RCS, so Table 1 presents an approximate reduction in delinquency taxes. Table 1 shows the effect of delinquent tax reduction after Korea introduced the RCS. The delinquency ratio of VAT is higher than that of Corporate or Individual Income Tax, but it is observed that the delinquency ratio of VAT decreases after the introduction of the RCS.

Table 1. Delinquent Tax Ratio by Major Tax Items.

\begin{tabular}{cccc}
\hline Period & VAT & Corporate Tax & Individual Income Tax \\
\hline FY2006-08(a) & $13.10 \%$ & $3.60 \%$ & $9.30 \%$ \\
FY2009-11(b) & $11.30 \%$ & $3.40 \%$ & $10.30 \%$ \\
FY2012-15(c) & $10.30 \%$ & $2.90 \%$ & $8.40 \%$ \\
\hline Changes $(\mathrm{c}-\mathrm{a}) / \mathrm{a}$ & $-21.37 \%$ point & $-19.44 \%$ point & $-9.68 \%$ point \\
\hline \multicolumn{5}{r}{ Source: Statistics of NTS. }
\end{tabular}

Prior to the introduction of the RCS, VAT was the highest delinquent tax in 2006-2008 (delinquent tax rate of $13.1 \%$ ). However, the ratio of delinquent tax for three years immediately after the introduction of the RCS was reduced to $11.3 \%$. The gold, copper and steel sectors also fell to $10.3 \%$ during the period when the RCS was introduced (2012-2015). Thus, the effect of introducing the RCS reduces the delinquency ratio by $21.37 \%$ point $[=(10.30-13.10) / 13.10 \times 100]$.

\subsection{Hypothesis Development}

The hypothesis was developed to address the relationship between trade transparency and SMEs as an outcome of the implementation of the RCS. The RCS has been applied by the taxation authorities to items that have been dealt with in industries prone to tax evasion, cash transactions, and high delinquency rates. Metal scrap is one of them. The RCS was introduced as an effort to legalize the tax base by securing trade transparency [19]. Defined by the dictionary as "a quality or condition 
of being clear and see-through," the term transparency is used to describe everyday objects, but has been adopted as a word describing the comprehensive concept of legislative and procedural transparency $[20,21]$. The discourse of transparency first appeared in the government and the public sector beginning with its discussion by the European Counsel in 1992 [22]. Park [23] and Niehoff and Moorman [24] have defined administrative transparency as being (1) easily identifiable or discovered by external stakeholders, (2) known clearly and publicly (3) free of concealment, manipulation and deception, and (4) easily understandable.

The definition of transparency used in this study is "the quality with which a transaction activity of a statutory item can be seen clearly to its core." The application of the RCS to a certain item allows the government to monitor its transactions without any fault, enhancing trade transparency by eliminating transactions without records and missing traders [3]. The buyer often has lesser bargaining power than the seller or vendor, especially in the case of SMEs. Hence, it is expected that SME buyers will sense the improvement in trade transparency to a greater degree. According to the political cost hypothesis, larger corporations have high trade transparency due to their constant exposure to external monitoring and competition [25]. Meanwhile, SMEs, whose perceived trade transparency was low at the time of introduction of the RCS, are likely to be more wary of the increased trade transparency. In perspective of VAT, trade transparency means the difference between the actual transaction amount and the transaction amount in the tax report. Trade transparency will be low because the amount of VAT declaration differs from the actual transaction amount of goods or services due to bargaining power, tax avoidance incentives or institutional problems between traders. Therefore, this study expects to develop the hypothesis that the level of trade transparency will be increased because of the same amount in the tax report due to RCS.

Hypothesis 1. SMEs that adopted the RCS perceive that trade transparency is higher.

The RCS was introduced to prevent missing companies from disrupting the trading order and evading VAT. One missing company in a VAT chain can muddle up its transactions and lead to the financial detriment of one party or another. Hence, it is necessary to assess where the introduction of the RCS has improved trade fairness. Fairness, in general, can be placed in one of three categories: distributive, procedural, or interaction $[3,26]$. Trade fairness is considered procedural and is an evaluation of the transactional procedure from beginning to end [27]. In other words, it is an evaluation of the fairness of the transaction concerning the goods and services, or whether the bargaining power was balanced. In terms of VAT, trade unfairness arises from the asymmetry of bargaining power among traders. If a trader has significantly higher power than other trader, it will be an unfair factor in the transaction amount or VAT return. For example, a trader with a strong power may gain economic benefits by under-reporting the actual sales size or by over-reporting the credit amount, but the counter trader must take economic losses accordingly. Prior to the introduction of RCS in this trade, the barging power of SMEs was relatively low. However, this study expects that the bargaining power between both traders will improve to a symmetrical structure as the effect of introduction of RCS. In particular, trade fairness is likely to be related to transparency. Because the bargaining power between trading partners influences these two concepts, the correlation between these two variables is expected to be statistically significant.

This study will focus on the procedural fairness as a result of the implementation of the RCS as perceived by entrepreneurs. Copper and steel scraps are by-products of rolled steel production or steel product processing that are collected to be reintroduced into the steel manufacturing line. Scrap trading begins with the buyer making a purchase offer to the seller, to which the seller responds by accepting or rejecting, and concludes with price negotiation. The seller has the upper hand in the transaction. With the conventional VAT system, the seller collects the VAT from the buyer and gives it to the tax office. If the seller goes missing or becomes delinquent in the process, the buyer is held 
responsible for the damages incurred. In the case of the RCS in VAT, the damage suffered by the buyer would be minimized as the seller must make a payment directly to the tax office.

Hypothesis 2. SMEs that adopted the RCS perceive that trade fairness is higher.

\section{Methodology and Data}

\subsection{Methodology}

In many studies on human perception or the qualitative effect, discrete models have been used to capture factors affecting the perception level or qualitative effect. Since the perception data are categorical in nature, some studies have relied on logistic regression, while others have used multinomial or nested logit models [28]. Recognizing that the discrete nature of perception of transparency and fairness is ordinal in nature, some studies have considered the ordered probit or ordered logit models to be more suitable. The choice in the use of ordered probit or ordered logit lies in the assumption of distribution of errors [28-30]. The ordered logit model is based on the assumption that the errors are independently and identically distributed with the logistic distribution whereas the ordered probit model is based on the assumption that the distribution of errors is multivariate normal. However, the results from the ordered probit can be fairly similar $[29,30]$.

Hence, ordered probit models can be used in this study. The ordered probit model is employed in this regard. The theoretical framework of the ordered probit model including the modelling, process, and method of evaluation has been thoroughly discussed in many studies [28]. Therefore, the general specification and process are as below.

The perception levels of trade transparency or fairness are classified into different proportion categories (i.e., 1: not likely at all, 2: not likely, 3: normal, 4: likely yes, 5: highly likely), in terms of respondent levels [31]. These categories are typically considered as ordinal outcomes (i.e., from the Not likely at all (1) of trade transparency or fairness to the highly likely). Ordered discrete choice models are generally used to analyze such ordinal response data. Among these models, the ordered probit $(\mathrm{OP})$ is the most commonly used approach $[32,33]$. Let $\mathrm{y}_{n i}$ be the perception level of trade transparency or fairness $n$ by respondent $i$. The OP model assumes that the perception level can be represented by a latent and continuous variable $\left(\mathrm{y}_{n i}^{*}\right)$, which is related to $\mathrm{X}_{n i}$ given as:

$$
\mathrm{y}_{n i}^{*}=\mathrm{X}_{n i} \beta+\varepsilon_{n i} \forall_{i}
$$

where $X_{n i}$ is a vector of explanatory variables, $\beta$ is a vector of unknown parameters to be estimated, and $\varepsilon_{n i}$ is the random error term capturing the effect of unobserved factors, which is assumed to follow a normal distribution with zero mean and unit variance [31].

In the respondent's survey data presented in this study, the perception levels of taxpayers (SMEs) are scaled to 5 levels: (1) not likely at all, (2) not likely, (3) normal, (4) likely yes, and (5) highly likely of trade transparency or fairness. The independent variables (i.e., purchase activities, size of taxpayer's compliance costs advice from tax experts, location, and industry) are then ordered with dummy or several categories. For SME's perception level $n$ to occur from respondent $i$, the observed perception level $\left(\mathrm{y}_{n i}\right)$ is related to an unobserved (latent) variable $\left(\mathrm{y}_{n i}^{*}\right)$ and is expressed as follows:

$$
\mathrm{y}_{n i}=\mathrm{j} \Rightarrow \mu_{j-1} \leq \mathrm{y}_{n i}^{*} \leq \mu_{j} \Leftrightarrow\left(\begin{array}{l}
1 \text { if } \mathrm{y}_{n i}^{*}={ }^{\prime} \text { Not likely at all' of trade transparency or fairness } \\
2 \text { if } \mathrm{y}_{n i}^{*}={ }^{\prime} \text { Not likely' of trade transparency or fairness } \\
3 \text { if } \mathrm{y}_{n i}^{*}={ }^{\prime} \text { Normal' of trade transparency or fairness } \\
4 \text { if } \mathrm{y}_{n i}^{*}={ }^{\prime} \text { Likely Yes of trade transparency or fairness } \\
5 \text { if } \mathrm{y}_{n i}^{*}={ }^{\prime} \text { Highly likely Yes' of trade transparency or fairness }
\end{array}\right.
$$


where $\mathrm{j}$ is the number of SMEs' perception levels (in this case, $j=5$ ); $\mu_{1}, \mu_{2}, \mu_{3}, \mu_{4}$, and $\mu_{5}$ are unknown threshold parameters to be estimated. The predicted probabilities of the perception level $j(j=1,2,3,4,5)$ can be estimated as:

$$
\mathrm{P}\left(\mathrm{Y}_{n i}=\mathrm{j}\right)=\mathrm{F}\left(\mu_{j}-\mathrm{X}_{n i}^{\prime} \beta\right)-\mathrm{F}\left(\mu_{j-1}-\mathrm{X}_{n i}^{\prime} \beta\right)
$$

where $\mathrm{F}(\cdot)$ is the standard normal cumulative distribution function. The model parameters (e.g., $\beta$ and $\mathrm{y}_{n i}^{*}$ ) are estimated by the method of maximum likelihood. The marginal effects of the ordered probit model with respect to explanatory variable $1\left(\beta_{l}\right)$ can be estimated as:

$$
\mathrm{ME}_{J l \mid \mathrm{X} l}=\frac{\partial \mathrm{P}\left(\mathrm{Y}_{n l}=\mathrm{j} \mid \mathrm{X}_{n i}\right)}{\partial X_{I l}}=\left[f\left(\mu_{j-1}-X_{n i}^{\prime} \beta\right)-f\left(\mu_{j}-X_{n i}^{\prime} \beta\right)\right] \cdot \beta_{l}
$$

where $f(\cdot)$ is the density function.

This study aims to analyze the perception held by SME taxpayers with regard to the effects of implementing the RCS on trade transparency and fairness. The ordered probit model, as shown in Equation (5), is used as the research model for empirical evaluation.

The dependent variable is the perception of SME taxpayers of the effect of the RCS on trade transparency and fairness, measured on a five-points Likert scale (1: Not likely at all. 2: not likely 3: normal 4: Likely yes 5: highly likely). The main interest variable is SME taxpayer and is synonymous with the amount of revenue that the taxpayer makes. This variable is measured on a 10-point Likert scale where revenue less than 100 million KRW is considered " 10 " and any greater than 50 billion KRW as " 1 " A value closer to " 10 " indicates a higher likelihood of the taxpayer being an SME.

Among the control variables based on Chung and Yoon [31], Purchase_Activity is defined as 1 if the amount of purchased gold, copper, and steel scrap is greater than the amount sold, and 0 if not. Compliance_Cost refers to the transaction fee that the taxpayer must pay the bank under the RCS. The level of burden felt by the taxpayer with respect to this fee is measured on a 5-point Likert scale (1: not burdensome at all, 2: not burdensome, 3: neutral, 4: burdensome, 5: very burdensome). Expert_Advice is defined as " 1 " if the taxpayer had received consultation on RCS transaction from a tax expert, and " 0 " if not. Location refers to the taxpayer's whereabouts and is a dummy variable. Industry refers to the taxpayer's field of work or industry and is also a dummy variable, and includes construction, demolition, second hand retail, recycled material collection and selling, metal manufacturing, metal wholesaling, automobile-related manufacturing, electronics manufacturing, and others.

Trade_Transparency or Trade_Fairness $_{i}=\beta_{0}+\beta_{1}$ SME_Taxpayer $_{i}+\beta_{2}$ Purchase_Activity $_{i}$ $+\beta_{3}$ Compliance_Cost $_{i}+\beta_{4}$ Expert_Advice $_{i}+\beta \sum$ Location $_{i}+\beta \sum$ Industry $_{i}+\varepsilon_{i}$

where,

Trade_Transparency: perceived increase in trade transparency (Trade_Transparency1: Increased transparency with RCS, Trade_Transparency2: The degree to which counter traders recognize that transparency has increased with RCS) following the implementation of VAT RCS; measured on the scale of very much (5), somewhat (4), neutral (3), not really (2), not at all (1) (5 Likert scale).

Trade_Fairness: perceived increase in the level of fair trade (Trade_Fairness1: Increased fairness with RCS, Trade_Fairness2: The degree to which counter traders recognize that fairness has increased with RCS) following the implementation of VAT RCS; measured on the scale of very much (5), somewhat (4), neutral (3), not really (2), not at all (1) (5 Likert scale)

$S M E \_$Taxpayer: variable related to SMEs and representing firm size. Less than 100 million KRW “10," 100 million-1 billion KRW “9," 1-3 billion KRW “8," 3-5 billion KRW “7," 5-7 billion KRW “6," 7-9 billion KRW “5," 9-15 billion KRW “4," 15-30 billion KRW “3," 30-50 billion KRW “2," more than 50 billion KRW “1." 
Purchase_Activity: " 1 " if the amount of gold, copper and steel scrap bought is greater than the amount sold, " 0 " if not.

Compliance_Cost: the level of burden felt by the taxpayer with respect to the transaction fee payable to the bank under the RCS (5-point Likert scale) (1: not burdensome at all, 2: not burdensome, 3: neutral, 4: somewhat burdensome, 5: very burdensome)

Expert_Advice: "1" if the taxpayer has received consultation from a tax professional, " 0 " if not.

Location: dummy variable concerning the taxpayer's whereabouts.

Industry: dummy variable concerning the taxpayer's line of work or industry.

\subsection{Data}

The sample used in this study is obtained using a questionnaire survey of businesses trading in gold, copper, or steel scrap as listed by the NTS, circulated via mail. Since the purpose of this study is to analyze the taxpayer's perception of the effect of introducing RCS, survey data of RCS adopters are considered appropriate data for this study. The sample selection criterion of this study is selected as the company to which the RCS has been applied. This sample is composed of major companies, SMEs and proprietorship companies. This survey consisted of questions on trade transparency and fairness and the company's status as a result of VAT RCS.

Table 2 shows the sample distributions. Entrepreneurs in charge of corporations accounted for more than half of the total sample size with 912 persons (54.91\%), followed by private general taxpayers with 721 persons (43.41\%), private simplified taxpayers with 19 persons $(1.14 \%)$, public organization with one person $(0.06 \%)$ and others with 8 persons $(0.48 \%)$. As for business types, $86(5.31 \%)$ of the respondents are in the construction industry, $29(1.79 \%)$ in the demolition industry, $34(2.1 \%)$ in second hand retail, $522(32.2 \%)$ in recycled material collection and selling, $364(22.46 \%)$ in metal manufacturing, 91 (5.61\%) in metal wholesale, 125 (7.71\%) in automobile-related manufacturing, $148(9.13 \%)$ in electronics manufacturing and $22(13.7 \%)$ in others.

Table 2. Sample Distribution.

\begin{tabular}{|c|c|c|c|}
\hline Variables & Characteristics & Frequency & Ratio \\
\hline \multirow{6}{*}{ Business Type of VAT } & Corporate Taxpayer & 912 & $53.87 \%$ \\
\hline & Proprietorship Taxpayer & 721 & $42.59 \%$ \\
\hline & Small Proprietorship Taxpayer & 19 & $1.12 \%$ \\
\hline & Enterprise Owned by Government & 9 & $0.53 \%$ \\
\hline & No Responses & 32 & $1.89 \%$ \\
\hline & Total & 1693 & $100 \%$ \\
\hline \multirow{11}{*}{ Industry } & Construction & 86 & $5.08 \%$ \\
\hline & Building Dismantling Construction & 29 & $1.71 \%$ \\
\hline & Retail Store Services of Used Goods & 34 & $2.01 \%$ \\
\hline & Collection and Sale of Materials for Recycling & 522 & $30.83 \%$ \\
\hline & Metal Manufacturing & 364 & $21.50 \%$ \\
\hline & Wholesale Services of Metal & 91 & $5.38 \%$ \\
\hline & Automobile Manufacturing & 125 & $7.38 \%$ \\
\hline & Electronics Related Manufacturing & 148 & $8.74 \%$ \\
\hline & Others & 222 & $13.11 \%$ \\
\hline & No Responses & 72 & $4.25 \%$ \\
\hline & Total & 1693 & $100 \%$ \\
\hline
\end{tabular}




\section{Results of Empirical Analysis}

\subsection{Descriptive Statistics and Correlations of Major Variables}

In Table 3, which shows the Pearson correlation between the major variables, the trade transparency variables (Trade_Transparency 1 and Trade_Transparency2) are distributed from 1 to 5, with an average of 3.627 and 3.506, respectively. Trade fairness variables (Trade_Fairness1 and Trade_Fairness2) are also distributed across the range of 1 to 5 , with an average of 3.76 and 4.402 , respectively.

Table 3. Descriptive Statistics of Major Variables.

\begin{tabular}{cccccccc}
\hline Variables & Mean & STD & Min & Q1 & Med & Q3 & Max \\
\hline Trade_Transparency1 & 3.627 & 1.103 & 1 & 3 & 4 & 4 & 5 \\
Trade_Transparency2 & 3.506 & 1.078 & 1 & 3 & 4 & 4 & 5 \\
Trade_Fairness1 & 3.760 & 1.200 & 1 & 3 & 4 & 5 & 5 \\
Trade_Fairness2 & 4.402 & 0.979 & 1 & 4 & 5 & 5 & 5 \\
SME_Taxpayer & 2.964 & 2.386 & 1 & 1 & 2 & 4 & 9 \\
Purchase_Activity & 0.353 & 0.487 & 0 & 0 & 0 & 1 & 1 \\
Compliance_Cost & 2.582 & 1.240 & 1 & 1 & 3 & 3 & 5 \\
Expert_Advice & 0.211 & 0.408 & 0 & 0 & 0 & 0 & 1 \\
\hline
\end{tabular}

Note1 Definition of the variables is as follows: Trade_Transparency: perceived increase in trade transparency (Trade_Transparency1: Increased transparency with RCS, Trade_Transparency2: The degree to which counter traders recognize that transparency has increased with RCS) following the implementation of VAT RCS; measured on the scale of very much (5), somewhat (4), neutral (3), not really (2), not at all (1) (5 Likert scale). Trade_Fairness: perceived increase in the level of fair trade (Trade_Fairness1: Increased fairness with RCS, Trade_Fairness2: The degree to which counter traders recognize that fairness has increased with RCS) following the implementation of VAT RCS; measured on the scale of very much (5), somewhat (4), neutral (3), not really (2), not at all (1) (5 Likert scale). SME_Taxpayer: variable related to SMEs and representing firm size. Less than 100 million KRW "10," 100 million-1 billion KRW “9," 1-3 billion KRW "8," 3-5 billion KRW “7," 5-7 billion KRW “6," 7-9 billion KRW "5," 9-15 billion KRW "4," 15-30 billion KRW “3," 30-50 billion KRW “2," more than 50 billion KRW "1.". Purchase Activity: "1" if the amount of gold, copper and steel scrap bought is greater than the amount sold, "0" if not. Compliance_Cost: the level of burden felt by the taxpayer with respect to the transaction fee payable to the bank under the RCS (5-point Likert scale) (1: not burdensome at all, 2: not burdensome, 3: neutral, 4: somewhat burdensome, 5: very burdensome). Expert_Advice: "1" if the taxpayer has received consultation from a tax professional, "0" if not.

The most frequently used method to measure respondents' responses in social science is the Likert scale. Many prior studies favor the Likert equation because it is relatively easy to construct and can improve internal consistency. It is necessary to apply appropriate data analysis methods reflecting characteristics as categorical variables. Careful attention should be paid to the handling of general categorical variables, but more attention should be paid to the selection of models and the interpretation of estimation results, especially when a category appears at a high frequency. In other words, zero can be overly frequent, which is called zero-inflated data. Using the general statistical model for categorical data with excessive 0 values may result in distorted analysis or difficulty in interpreting the original meaning. In this study, the smallest value of the categorical data is defined as 1 . However, this value is less than $5 \%$ of the total, as confirmed in Table 3 . There is no problem of zero-inflated data. Therefore, this study concludes that there is no problem in applying the ordered probit model to analyze the degree of taxpayer's perception

Table 4 shows the results of the correlation analysis performed between the variables prior to the regression analysis. Trade transparency and fairness have a positive correlation (0.153 0.414) at the significance level of $1 \%$, indicating that SME taxpayers perceive transparency and fairness as being identically affected by the introduction of the RCS. The multicollinearity problem will not be serious, especially since the coefficient between these variables is less than 0.6. SME_Taxpayer, the interest variable, is found to have a positive and statistically significant correlation (0.123 0.175) with transparency and fairness. This demonstrates that SME taxpayers perceive the effects of the RCS on trade transparency and fairness positively, indicating improvement in both areas. Purchase_Activity and Compliance_Cost, which are the control variables, also demonstrate statistically significant results. Compliance_Cost in particular shows a negative correlation, meaning that the larger the amount of bank 
fee the taxpayer must pay as a result of the RCS, the more negatively the taxpayer's perception will be with respect to the effect of the RCS on trade transparency and fairness [1].

Table 4. Pearson's Correlation among Major Variables.

\begin{tabular}{|c|c|c|c|c|c|c|c|}
\hline Variables & $\begin{array}{c}\text { Trade_ } \\
\text { Transparency1 }\end{array}$ & $\begin{array}{c}\text { Trade } \\
\text { Transparency2 }\end{array}$ & $\begin{array}{c}\text { Trade_ } \\
\text { Fairness1 }\end{array}$ & $\begin{array}{c}\text { Trade } \\
\text { Fairness2 }\end{array}$ & $\begin{array}{c}\text { SME } \\
\text { Taxpayer }\end{array}$ & $\begin{array}{l}\text { Purchase } \\
\text { Activity }\end{array}$ & $\begin{array}{l}\text { Compliance } \\
\text { Costs }\end{array}$ \\
\hline Trade_Transparency2 & $\begin{array}{c}0.681^{* * *} \\
(0.000)\end{array}$ & 1 & & & & & \\
\hline Trade_Fairness1 & $\begin{array}{c}0.220^{* * *} \\
(0.000)\end{array}$ & $\begin{array}{c}0.236^{* * *} \\
(0.000)\end{array}$ & 1 & & & & \\
\hline Trade_Fairness2 & $\begin{array}{c}0.153^{* * *} \\
(0.000)\end{array}$ & $\begin{array}{c}0.156^{* * *} \\
(0.000)\end{array}$ & $\begin{array}{c}0.414 \text { *** } \\
(0.000)\end{array}$ & 1 & & & \\
\hline SME_Taxpayer & $\begin{array}{c}0.128^{* * *} \\
(0.000)\end{array}$ & $\begin{array}{c}0.123^{* * *} \\
(0.000)\end{array}$ & $\begin{array}{c}0.175^{* * *} \\
(0.000)\end{array}$ & $\begin{array}{c}0.142 * * * \\
(0.000)\end{array}$ & 1 & & \\
\hline Purchase_Activity & $\begin{array}{l}0.047^{*} \\
(0.054)\end{array}$ & $\begin{array}{l}-0.013 \\
(0.597)\end{array}$ & $\begin{array}{c}0.073^{* * * *} \\
(0.003)\end{array}$ & $\begin{array}{c}-0.046^{*} \\
(0.056)\end{array}$ & $\begin{array}{c}0.037 \\
(0.143)\end{array}$ & 1 & \\
\hline Compliance_Cost & $\begin{array}{l}-0.143^{* * *} \\
(0.000)\end{array}$ & $\begin{array}{c}-0.171^{* * *} \\
(0.000)\end{array}$ & $\begin{array}{l}-0.215^{* * *} \\
(0.000)\end{array}$ & $\begin{array}{l}-0.114^{* * *} \\
(0.000)\end{array}$ & $\begin{array}{c}-0.045^{*} \\
(0.080)\end{array}$ & $\begin{array}{c}0.031 \\
(0.212)\end{array}$ & 1 \\
\hline Expert_Advice & $\begin{array}{l}-0.002 \\
(0.926)\end{array}$ & $\begin{array}{l}-0.029 \\
(0.230)\end{array}$ & $\begin{array}{c}0.026 \\
(0.281)\end{array}$ & $\begin{array}{l}-0.017 \\
(0.489)\end{array}$ & $\begin{array}{c}-0.083^{* * *} \\
(0.001)\end{array}$ & $\begin{array}{c}0.028 \\
(0.256)\end{array}$ & $\begin{array}{l}0.041 * \\
(0.096)\end{array}$ \\
\hline
\end{tabular}

Note ${ }^{* * *},{ }^{* *}$, and ${ }^{*}$ indicate statistical significance at the $1 \%, 5 \%$ and $10 \%$ two-tailed level, respectively. And definition of the variables is as note1) of Table 3.

\subsection{Results of Probit Regression Analysis}

Table 5 shows the results of the probit regression performed in order to test hypothesis 1 related to the effect of the RCS on trade transparency. SME_Taxpayer is found to have a value of 0.039 ( $p$-value $<0.000)$ and $0.032(p$-value $<0.000)$ with respect to Trade_Transparency1 and Trade_Transparency2, respectively. This indicates that smaller companies usually have lower levels of trade transparency, and are hence more wary of the positive changes brought on by the introduction of the RCS. Hence, this analysis supports hypothesis 1 that there is a positive relationship between trade transparency and SME taxpayer. Compliance_Cost is found to have coefficients of -0.101 ( $p$-value $<0.000$ ) and -0.117 ( $p$-value $<0.000)$, demonstrating that the bank fee associated with the application of the RCS serves as a negative factor by imparting a burden on the taxpayer. This result is consistent with the analysis of Jung and Yoon [1] that taxpayer's satisfaction level is lower as compliance costs are higher.

Table 5. The Effects of the Reverse Charge System (RCS)'s Adoption on Trade Transparency of small and medium enterprises (SMEs).

\begin{tabular}{|c|c|c|c|c|c|c|}
\hline \multirow{2}{*}{ Variables } & \multicolumn{3}{|c|}{ Trade_Transparency1 } & \multicolumn{3}{|c|}{ Trade_Transparency 2} \\
\hline & Coefficient & Wald $X^{2}$ & $p$-Value & Coefficient & Wald $X^{2}$ & $p$-Value \\
\hline Intercept 1 & $-1.881^{* * *}$ & 43.32 & 0.000 & $-2.057 * * *$ & 51.83 & 0.000 \\
\hline Intercept 2 & $0.428^{* * *}$ & 112.28 & 0.000 & $0.468^{* * *}$ & 128.07 & 0.000 \\
\hline Intercept 3 & $1.403^{* * *}$ & 675.41 & 0.000 & $1.525^{* * *}$ & 776.80 & 0.000 \\
\hline Intercept 4 & $2.402^{* * *}$ & 1545.25 & 0.000 & $2.612^{* * *}$ & 1708.53 & 0.000 \\
\hline SME_Taxpayer & $0.039 * * *$ & 10.30 & 0.000 & $0.032 * * *$ & 6.79 & 0.009 \\
\hline Purchase_Activity & 0.068 & 1.18 & 0.476 & 0.053 & 0.70 & 0.401 \\
\hline Compliance_Cost & $-0.101^{* * *}$ & 18.58 & 0.000 & $-0.117^{* * *}$ & 25.28 & 0.000 \\
\hline Expert_Advice & 0.057 & 0.01 & 0.548 & 0.057 & 0.68 & 0.410 \\
\hline ELocation & & Included & & & Included & \\
\hline$\sum I N D$ & & Included & & & Included & \\
\hline Log Likelihood Ratio & & -2062.94 & & & -2044.39 & \\
\hline Observation & & 1693 & & & 1693 & \\
\hline
\end{tabular}

Note ${ }^{* * *}, * *$ and $*$ indicate statistical significance at the $1 \%, 5 \%$ and $10 \%$ two-tailed level, respectively. And definition of the variables is as note 1 of Table 3 .

Table 6 demonstrates the effects of the introduction of the RCS on trade fairness, showing the results of the probit regression analysis performed to test hypothesis 2. SME_Taxpayer is found to be 
$0.047(p$-value $<0.000)$ and $0.052(p$-value $<0.000)$ in relation to Trade_Fairness1 and Trade_Fairness2, respectively. This demonstrates that smaller firms, which are often subject to unfair treatment, are more likely to sense the positive effects that the introduction of the RCS exerts on trade fairness. Hence, this analysis supports hypothesis 2 . Compliance_Cost is found to have coefficients of -0.153 ( $p$-value $<0.000$ ) and -0.055 ( $p$-value $<0.05)$ as shown in Table 5, demonstrating that the bank fee associated with the application of the RCS serves as a negative factor by imparting a burden on the taxpayer.

Table 6. The Effects of the RCS's Adoption on Trade Fairness of SMEs.

\begin{tabular}{|c|c|c|c|c|c|c|}
\hline \multirow{2}{*}{ Variables } & \multicolumn{3}{|c|}{ Trade Fairness1 } & \multicolumn{3}{|c|}{ Trade Fairness2 } \\
\hline & Coefficient & Wald $X^{2}$ & $p$-Value & Coefficient & Wald $X^{2}$ & $p$-Value \\
\hline Intercept 1 & $-1.016^{* * *}$ & 11.29 & 0.000 & 0.203 & 0.32 & 0.574 \\
\hline Intercept 2 & $0.880^{* * *}$ & 616.56 & 0.000 & $0.705^{* * *}$ & 374.66 & 0.000 \\
\hline Intercept 3 & $1.552^{* * *}$ & 1099.95 & 0.000 & $1.171^{* * *}$ & 529.92 & 0.000 \\
\hline Intercept 4 & $2.248^{* * *}$ & 1210.77 & 0.000 & $1.886^{* * *}$ & 469.98 & 0.000 \\
\hline SME_Taxpayer & $0.047^{* * *}$ & 14.32 & 0.000 & $0.052 * * *$ & 12.33 & 0.000 \\
\hline Purchase_Activity & -0.019 & 0.090 & 0.765 & -0.030 & 0.17 & 0.677 \\
\hline Compliance_Cost & $-0.153^{* * *}$ & 41.71 & 0.000 & $-0.055^{* *}$ & 4.14 & 0.042 \\
\hline Expert_Advice & 0.059 & 0.70 & 0.102 & 0.048 & 0.37 & 0.543 \\
\hline$\sum$ Location & & Included & & & Included & \\
\hline$\sum I N D$ & & Included & & & Included & \\
\hline Log Likelihood Ratio & & -2037.57 & & & -1482.32 & \\
\hline Observation & & 1693 & & & 1693 & \\
\hline
\end{tabular}

Note ${ }^{* * *}, * *$, and * indicate statistical significance at the $1 \%, 5 \%$ and $10 \%$ two-tailed level, respectively. And definition of the variables is as note 1 of Table 3 .

The marginal effect of Trade Transaction 1 and Trade Transaction 2 was $0.0359,0.0321$ respectively, and Trade Fairness1 (Trade Fairness2) was 0.0451 (0.0513). This shows that the SME taxpayer recognizes higher transparency and fairness (e.g., 3.3 5.1\%) resulting from RCS acquisition.

\section{Conclusions}

With a focus on VAT, which makes up the bulk of tax revenue worldwide, this study analyzes the innovative effects of converting the VAT system into an RCS. Past literature has postulated that the implementation of the RCS for preventing tax avoidance through the black-market and MTIC fraud would benefit SMEs that supply goods or provide services by enhancing trade transparency and fairness. However, such literature has not provided empirical or quantitative evidence to support these claims. Indeed, the delinquent tax ratio of VAT has dramatically decreased from $13.1 \%$ to $10.3 \%$ since the introduction of the RCS. This study analyzes the effects of the RCS through the analysis of attitudes and perceptions held by the actual parties involved in the transaction.

This study is an analysis of the perception of trade transparency and fairness by SMEs as a result of the introduction of the RCS to the South Korean VAT system. The findings are as follows.

First, SME taxpayers are more likely to perceive trade transparency as being enhanced after the introduction of the RCS. In the transactions between companies handling gold, copper and steel scraps, SMEs have often suffered at the hands of larger companies who abuse their relatively stronger bargaining power to avoid paying VAT or cutting the price to be equal to the VAT, leading to poor transparency in trade. SME taxpayers perceive that the RCS has improved trade transparency. Such results provide empirical evidence that the RCS may be beneficial in ensuring trade fairness not only in South Korea, which applied the RCS, but elsewhere, as well.

Second, SME taxpayers are more likely to perceive improvements in trade fairness as an outcome of the RCS. Imbalances in the bargaining power of trade in gold, copper and steel scraps often deprive one of the parties involved of the full benefits of the transaction. The trader with relatively weaker bargaining power is usually the SME, and may suffer as a result of unfair trade practices such as price 
cutting and imposition of VAT. SME taxpayers perceive trade fairness to have improved since the adoption of the RCS.

The results of this study demonstrate the positive effects of the RCS on SMEs. While such effects may be applicable to taxpayers of larger corporations as well, it is possible that they respond negatively to the survey questionnaire because the privileges formerly enjoyed by them have been reduced by the introduction of the RCS. As mentioned in the introduction of the RCS in this study, the larger corporations had relatively large benefits before the adoption of the RCS, and these corporations received more benefits than the SMEs due to the low fairness and transparency level of transactions. However, after the adoption of the RCS, the benefits were relatively reduced due to this trade fairness and transparency.

However, this study emphasizes minimizing the compliance costs that taxpayers must bear in order to have a positive RCS effect. In the analysis results, compliance costs have a negative relationship with the trade fairness or transparency. That is, it is necessary to minimize compliance costs such as bank and card fees, and provide incentives such as tax credits for the RCS.

Funding: This research received no external funding.

Conflicts of Interest: The author declares no conflicts of interest.

\section{References}

1. Chung, J.S.; Yoon, S.M. The Determinants of Taxpayer's Satisfaction of Reverse Charge System and Bank Service: Case of Korean Value-Added Tax. Int. J. Appl. Eng. Res. 2015, 10, 31649-31662.

2. Ki, E.S.; Koo, J.E.; Park, M.H. A Study on Reform of VAT Reverse Charge Mechanism. Korean J. Tax. Res. 2015, 32, 139-165. (In Korean)

3. Lee, H.W. Reconsidering the Concept of Transparency in Policy. J. Inst. Soc. Sci. 2016, 27, 117-142. (In Korean) [CrossRef]

4. HRMS. VAT Notice 735: VAT Domestic Reverse Charge on Specified Goods and Services. UK, 2015. Available online: https:/ / www.gov.uk/guidance/the-vat-domestic-reverse-charge-procedure-notice-735\# para9 (accessed on 13 March 2018).

5. Iyer, P.; Davari, A.; Paswan, A. Perceived price fairness and price decay in the DVD market. Green products: Altruism, economics, price fairness and purchase intention. Soc. Bus. 2016, 6, 39-64. [CrossRef]

6. Lúðvík, L. VAT Frauds in the European Union: The Reverse Charge Mechanism, Joint and Several Liability and the "Knowledge Test". Master's Thesis, Lund University, Longde, Sweden, 2012.

7. Kim, K.S.; Jeon, B.W. The Evasions of Gold Bullion Trades and Its Improvements. Korean Res. Tax. Law 2007, 12, 340-374. (In Korean)

8. Kim, J.J.; Hong, S.Y.; Lee, H.M. Review of Problem and Effect of RCS Adoption in Steel Scrap. Korean Res. Tax. Law 2015, 15, 2-75. (In Korean)

9. Milošković, A.; Dojčinović, B.; Kovačević, S.; Radojković, N.; Radenković, M.; Milošević, D.; Simić, V. Spatial monitoring of heavy metals in the inland waters of Serbia: A multi-species approach based on commercial fish. Environ. Sci. Pollut. Res. 2016, 23, 9918-9933. [CrossRef] [PubMed]

10. Ainsworth, R.T. The Morphing of MTIC Fraud: VAT Fraud Infects Tradable $\mathrm{CO}_{2}$ Permits. Boston University School of Law. 2009. Available online: https:/ / ssrn.com/abstract=14432792 (accessed on 22 February 2018).

11. Zee, H.H. A New Approach to Taxing Financial Intermediation Services Under a Value-Added Tax. 2005. Available online: https:/ / www.jstor.org/stable/41790176 (accessed on 13 March 2018).

12. Ainsworth, R.T.; Musaad, A. GCC VAT: The Intra-Gulf Trade Problem. 2016. Available online: https://ssrn.com/abstract=2916252 (accessed on 20 August 2016).

13. Poniatowski, G.; Bonch-Osmolovskiy, M.; Misha, B. Study and Reports on the VAT Gap in the EU-28 Member States: 2016 Final Report. 2016. Available online: https:/ / ssrn.com/abstract=2847658 (accessed on 4 April 2018).

14. Lamensch, M. Are 'reverse charging' and the 'one-stop-scheme' efficient ways to collect VAT on digital supplies? World J. VAT/GST Law 2012, 1, 1-12. [CrossRef] 
15. Hrdinková, M. Reverse Charge Method in the Environment of Harmonized VAT. Ministry of Finance of the Czech Republic Report (Closing VAT GAP through Reverse Charge Mechanism). 2015. Available online: https:/ / www.mfcr.cz/en/news/news/2016/collection-of-the-tax-conference-23757 (accessed on 28 October 2018).

16. Chung, J.S.; Yoon, S.M. A Study on Applying VAT Charge System Using Credit Card Companies. Korean Tax Account. J. 2016, 17, 163-192. (In Korean)

17. OECD Consumption. Consumption Tax Trends 2010 VAT/GST and Excise Rates, Trends and Administration Issues; OECD Publishing: Paris, France, 2011.

18. European Commission. Assessment of the Application and Impact of the Optional 'Reverse Charge Mechanism' within the EU VAT System. 2014. Available online: https:/ / ec.europa.eu/taxation_customs / sites /taxation/files/resources / documents/common/publications/studies /kp_07_14_060_en.pdf (accessed on 17 March 2018).

19. Statistics of NTS. 2010-2017. Available online: https://www.nts.go.kr/info/info_05.asp (accessed on 3 March' 2018). (In Korean)

20. Park, H.S.; Hyun, N. The Effects of Transparency on Citizen Satisfaction with Civil Applications Administration. Korean J. Public Admin. 2010, 12, 385-406. (In Korean)

21. Jang, Y.S.; Song, E.Y. Changing Logics of Transparency in Korea, 1993 2006: A Content Analysis of Korean Newspaper Articles. Korean J. Sociol. 2008, 42, 146-177. (In Korean)

22. Zimmerman, J.L. Taxes and firm size. J. Account. Econ. 1983, 5, 119-149. [CrossRef]

23. Park, H.S. Improvement of Public Administration Transparency: The Case of Korea. Local Admin. Rev. 2000, 13, 39-57. (In Korean)

24. Niehoff, B.P.; Moorman, R.H. Justice as a mediator of the relationship between monitoring and organizational citizenship behavior. Acad. Manag. J. 1993, 36, 527-556.

25. Watts, R.; Zimmerman, J.L. Positive Accounting Theory; Edgewood Cliff: Bergen County, NJ, USA, 1986.

26. Greenberg, J. The social side of fairness: Interpersonal and informational classes of organizational justice. In Series in Applied Psychology. Justice in the Workplace: Approaching Fairness in Human Resource Management; Cropanzano, R., Ed.; Lawrence Erlbaum Associates, Inc.: Hillsdale, NJ, USA, 1993; pp. 79-103.

27. Lind, E.A.; Tyler, T.R. Critical issues in social justice. In The Social Psychology of Procedural Justice; Plenum Press: New York, NY, USA, 1988.

28. Rifaat, S.M.; Chin, H.C. Accident Severity Analysis Using Ordered Probit Model. J. Adv. Transp. 2007, 41, 91-114. [CrossRef]

29. O'Donnel, C.J.; Connor, D.H. Predicting the Severity of Motor Vehicle Accident Injuries Using Models of Ordered Multiple Choice. Accid. Anal. Prev. 1996, 28, 739-753. [CrossRef]

30. Renski, H.; Khattak, A.J.; Council, F.M. Impact of Speed Limit Increases on Crash Severity: Analysis of Single-Vehicle Crashes on North Carolina Interstate Highways. Transp. Res. Rec. 1999, 1665, 100-108. [CrossRef]

31. Kim, K.S.; Yoon, S.M. Taxpayer's Perception to Tax Payment in Kind System in Support of SMEs' Sustainability: Case of the South Korean Government's Valuation of Unlisted Stocks. Sustainability 2017, 9, 1523. [CrossRef]

32. Li, Z.; Liu, P.; Wang, W.; Xu, C. Using support vector machine models for crash injury severity analysis. Accid. Anal. Prev. 2012, 45, 478-486. [CrossRef] [PubMed]

33. Anarkooli, A.J.; Hosseinpour, M.; Kardar, A. Investigation of factors affecting the injury severity of single-vehicle rollover crashes: A random-effects generalized ordered probit model. Accid. Anal. Prev. 2017, 106, 399-410. [CrossRef] [PubMed]

(C) 2018 by the author. Licensee MDPI, Basel, Switzerland. This article is an open access article distributed under the terms and conditions of the Creative Commons Attribution (CC BY) license (http:/ / creativecommons.org/licenses/by/4.0/). 